\title{
Analysis and Calibration of Ground Penetrating Radar Shielded Antennas
}

\author{
Antenna Calibrations
}

\author{
Mezgeen Rasol \\ RMEE: Dept. Resist. de Mat. y \\ Estructuras en la Ingeniería \\ Universidad Politécnica de Cataluña \\ Barcelona, Spain \\ mezgeen.rasol@upc.edu
}

\author{
Vega Pérez-Gracia \\ RMEE: Dept. Resist. de Mat. y \\ Estructuras en la Ingeniería \\ Universidad Politécnica de Cataluña \\ Barcelona, Spain \\ vega.perez@upc.edu
}

\author{
Sonia Santos Assunção \\ RMEE: Dept. of Fluid Mechanics en la \\ Ingeniería \\ Universidad Politécnica de Cataluña \\ Barcelona, Spain \\ sonia.assuncao@upc.edu
}

\begin{abstract}
Ground-Penetrating Radar (GPR) is a non-destructive geophysical method applied in many civil engineering applications. The knowledge of the GPR antennas behavior is crucial to obtain accurate results and comprehensive data interpretations. However, the age of the antennas and the use can modify the values provided by manufacturers. Consequently, calibration of antennas is recommended. Calibration involves determining several parameters. In this paper, the evaluation of two parameters (stability of the signal and zero-time position) and the analysis of the effects of stacking are presented. Three antennas characterized by nominal center frequencies of $500 \mathrm{MHz}, 800 \mathrm{MHz}$ and $1.6 \mathrm{GHz}$ are analyzed. The direct wave was used for the stability analysis in two propagation media: air and concrete. The results of the stability evaluation seems to indicate that the emitted signal and the reconstruction of A-scans are quite stable and noise as consequence of electronic noise is low. Zero time position was measured in air, calculating the propagation time for the reflection on a metallic surface.
\end{abstract}

Keywords - GPR, antenna calibration, signal stability, stacking, zero-time position.

\section{INTRODUCTION}

Ground Penetrating Radar is a non-destructive test widely used in many civil engineering applications and in the study of the shallow geology. Different applications have been fully described by many researchers [e.g., 1, 2, 3]. And the methodology, processing algorithms and equipment is still being developed by several companies and research groups.

This method is based in the emission and reception of electromagnetic waves, obtaining images of the interior of medium. Complex media provide confuse images in many cases. Therefore, a successful radar data interpretation must involve also laboratory experiments and modelling [e.g., 4, 5, 6]. Both, experiment and computational models provide patterns that can be compared to field data, improving the final interpretation.

In addition, a successful survey and interpretation requires a wide knowledge of the antennas behaviour. Usually this preliminary calibration requires some laboratory tests which are designed in order to determine the zero, the stability and other characteristics of the signal. This paper presents some tests with the antennas of $500 \mathrm{MHz}, 800 \mathrm{MHz}$ and $1.6 \mathrm{GHz}$ in order to obtain some of the parameters of the signal.

\section{METHODOLOGY}

The laboratory tests were carried out in Escola d'Enginyeria de Barcelona Est (EEBE), in Barcelona, Spain. The purpose of this experimental works was obtaining data to analyse and calibrate several GPR antennas. Three parameters were studied: the zero-time position, the stability of the emitted signal and the comparison between different data stacking.

\section{A. Stability Test}

Many manufacturers provide information about the stability of the signal. However, the use and the age of the equipment can modify its behaviour, and calibration could be useful previous to any work $[7,8,9,10,11]$. Stability depends on the electronic effects, on the reconstruction of the signal and also on the clutter. The three effects introduce noise in the signal, increasing the difficult in the analysis of anomalies. Electronics and reconstruction of signals introduce a noise that depends only on the antenna characteristics, while clutter depends on the ground surface, on the media materials and on the targets. In this study, only the noise produced by electronics and signal reconstruction are analysed for three shielded antennas from Mala Geosciences: $500 \mathrm{MHz}, 800 \mathrm{MHz}$ and $1.6 \mathrm{GHz}$.

The analysis was done using two different propagation media: the air (first case) and the ground (second case).

First case: The air was used due to its homogeneity. In addition, the wave velocity in air is known [3] and can be assumed as $30 \mathrm{~cm} / \mathrm{ns}$. As air is a simple and homogeneous media, the radar images can be clean and easy to interpret, even though that clutter due to unwanted targets can be detected. A careful interpretation considering this difficult can provide information to calibrate the antennas [7,9]. Stability was determined by obtaining the direct wave from the emitter to the receiver. Three measurements were carried out during at least 30 seconds with $500 \mathrm{MHz}$ and $1600 \mathrm{MHz}$ centre frequency antennas, and 4 measurements with the $800 \mathrm{MHz}$ centre frequency antenna.

Second case; Ground was used to compare the stability results in material media with the results in air. The antenna was placed over a concrete floor (see figure 1). In this case the medium is heterogeneous, and radar data is expected more complicated and obscure. GPR measurements were carried out without moving the antenna, during at least 60 seconds, and in 
three different zones of the same floor. The tests require the clear detection of the direct wave which is coupled with the ground surface reflection. The objective is to define the stability of the measured amplitude of the first arrival or direct wave. As in the first case, three measurements were carried out during at least 30 seconds with $500 \mathrm{MHz}$ and $1600 \mathrm{MHz}$ centre frequency antennas, and 4 measurements with the $800 \mathrm{MHz}$ centre frequency antenna.

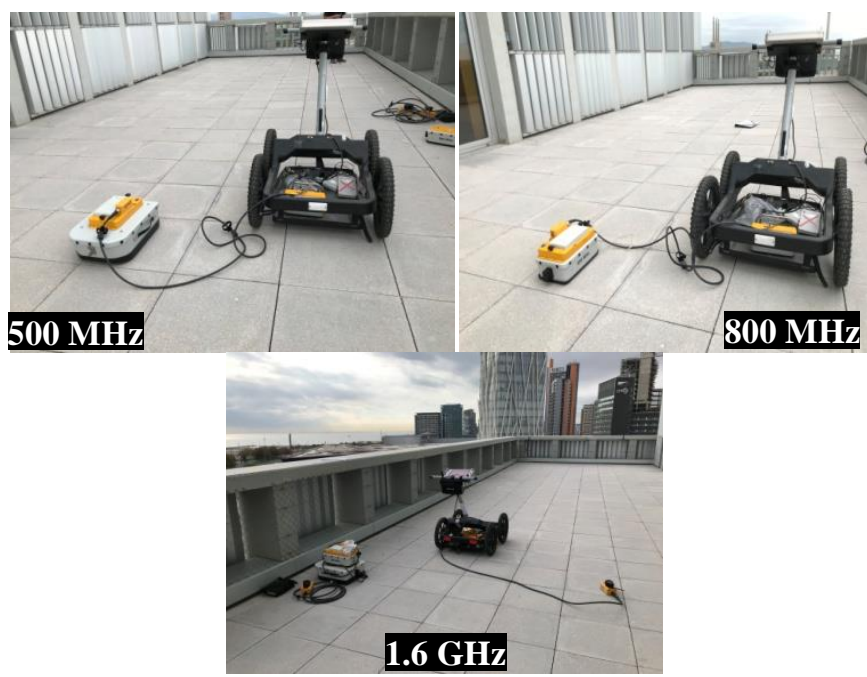

Fig. 1. Radar data acquisition in a concrete floor with $500 \mathrm{MHz}, 800 \mathrm{MHz}$ and 1.6 GHz GPR antennas, for the stability tests.

\section{B. Time Zero Test}

The conversion of two-way travel times into depths requires the selection of the zero-time position. This parameter is crucial in order to obtain accurate depths to the targets. Therefore, is an important test in the antennas calibration tasks. In this study three shielded antennas $(500 \mathrm{MHz}, 800 \mathrm{MHz}$ and $1.6 \mathrm{GHz})$ were tested. Measurements procedure was based on the reflection of the transmitted wave in air on a metal sheet. The antenna was placed on a wooden tripod installed at different distances from the metallic surface (see figure 2). The minimum distance between the plate and the antenna requires no-overlapping of the direct wave with the reflected wave. Radar data was acquired for approximately one minute.

The procedure (figure 3 ) of the test consist of:

- One antenna supported on the wooden stand, $75 \mathrm{~cm}$ distant from the floor. The surface of the antenna was oriented to the metal surface.

- Data acquisition was obtained with the antenna in a fixed position. Each measurement was carried out a a different distance: $240 \mathrm{~cm}, 120 \mathrm{~cm}$ and $60 \mathrm{~cm}$ for $500 \mathrm{MHz}, 800$ $\mathrm{MHz}$ and $1.6 \mathrm{GHz}$, respectively.

- A-scans shows clearly the direct wave and the reflected wave.
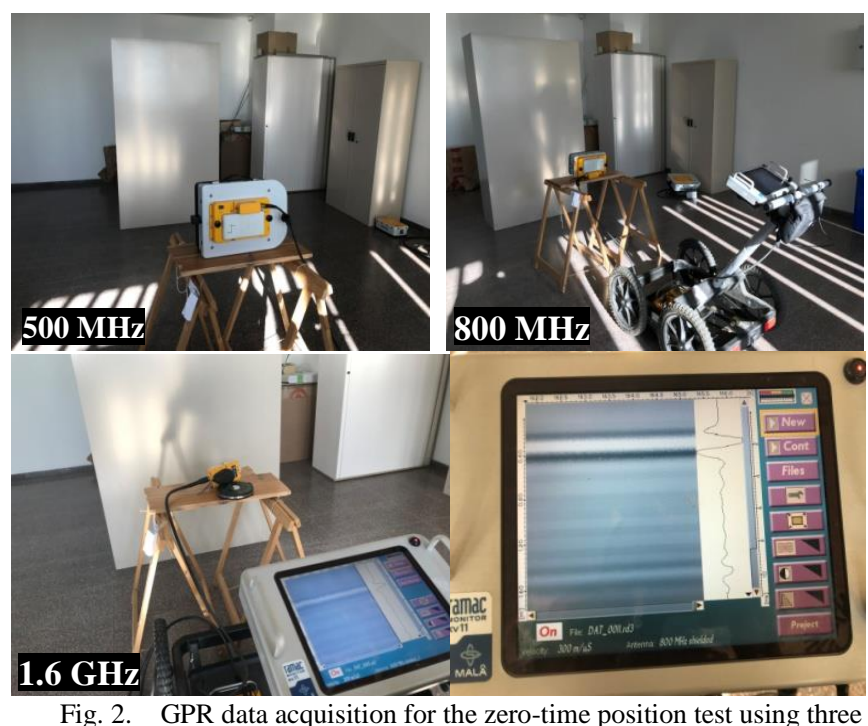

Fig. 2. GPR data acquisition for the zero-time position test using three antennas $(500 \mathrm{MHz}, 800 \mathrm{MHz}$ and $1.6 \mathrm{GHz})$.

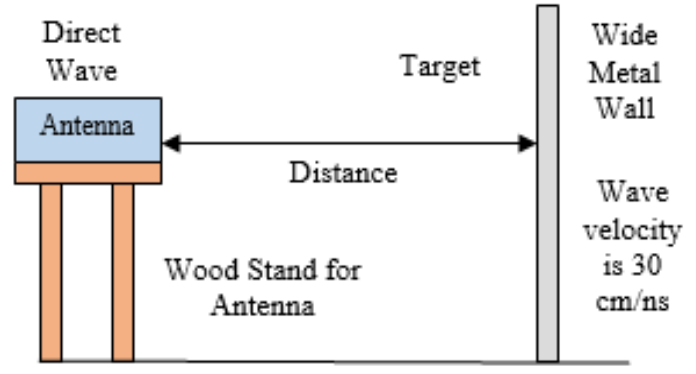

Surface Ground

Fig. 3. Scheme of the data acquisition procedure in the zero-time analysis.

The time zero can be determined by calculating the two-way travel time scale as describing in equation (1). figure 4 shows the procedure to assign the position of the zero-time at the Ascan. This zero is selected from the maximum of the reflected wave, measuring from this maximum the TWT obtained in equation (1).

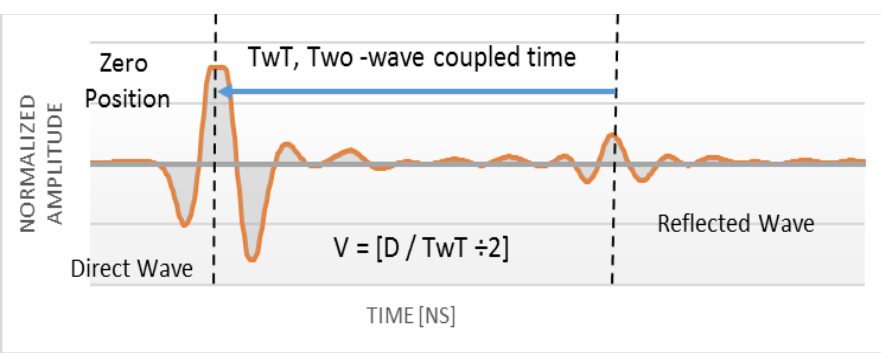

Fig. 4. Zero-time position is selected from the maximum of the reflected wave, measuring the TWT.

\section{Stacking Test}

This objective of this last test was to determine the effects on the radar images of the different stacking values. Radar data was acquired with three antennas $(500 \mathrm{MHz}, 800 \mathrm{MHz}$ and $1.6 \mathrm{GHz}$ nominal centre frequencies) on a concrete floor. The stacking values applied during data acquisition were 1,2,4,8,16,32,64,128, 256 and 512. All radar data were gathered with each GPR antenna in the same location and along the same radar line. 


\section{RESULTS}

\section{A. Stability}

The analysis was done by measuring the amplitude of the direct wave at each trace obtained during the three measurements carried out with each antenna in air and the three measurements on ground. The amplitude for each one of the measurements was divided by the maximum amplitude, obtaining a relative value. The results were presented in different graphs that show the change in the relative amplitude $(\Delta$ R.A) for each acquired A-scan or trace. Figures 5, 6 and 7 present the results in air and ground for each one of the calibrated antennas.

The results are summarized in table 1, at which the average result for each test is presented.

It is noticeable that the stability in both media, air and ground, decreases while the centre frequency increases for the tested antennas. The most stable is the wave emitted and received by the $500 \mathrm{MHz}$ nominal centre frequency antenna. However, in all cases, stability is high, being in all cases the change in the amplitude smaller than a $1 \%$ of the maximum measured amplitude. On the other hand, the measurements not detect significant differences between the case of air and the case of ground.
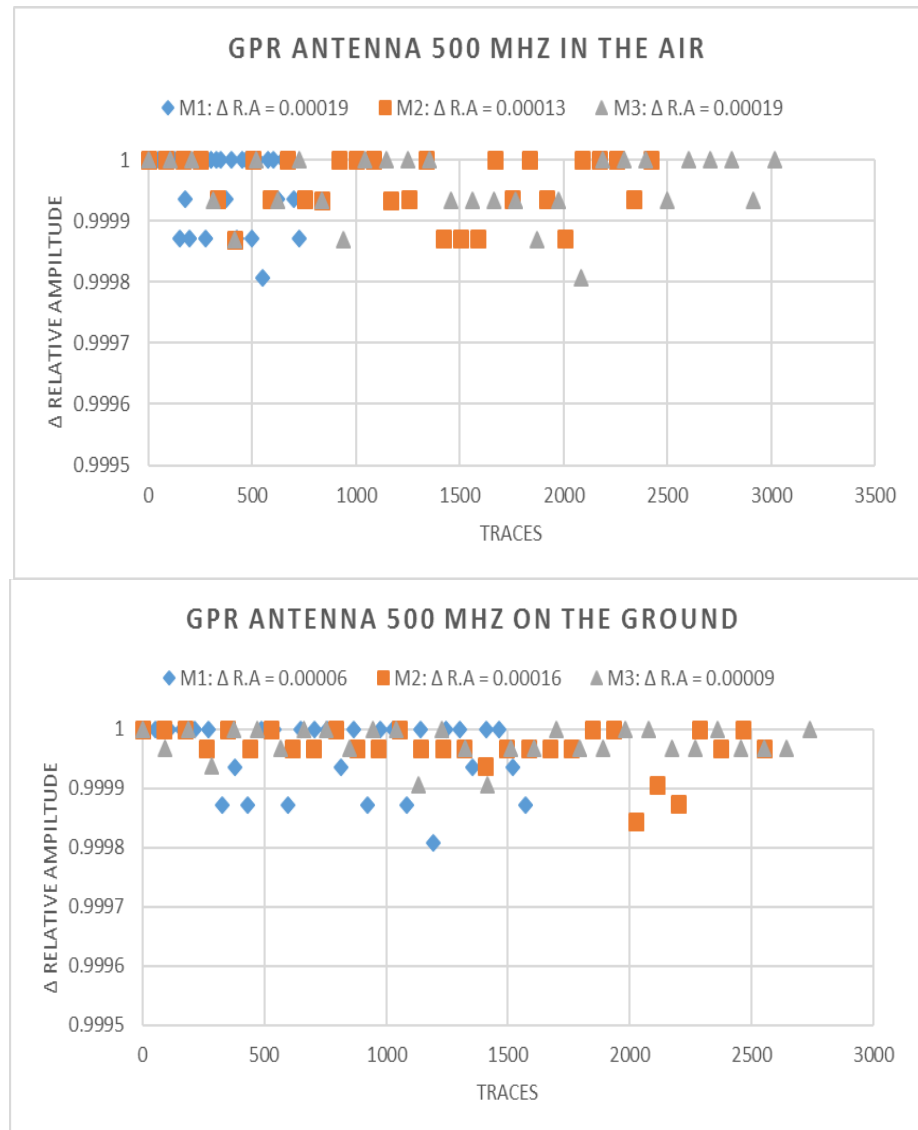

Fig. 5. Direct wave relative amplitude for the $500 \mathrm{MHz}$ centre frequency antenna.
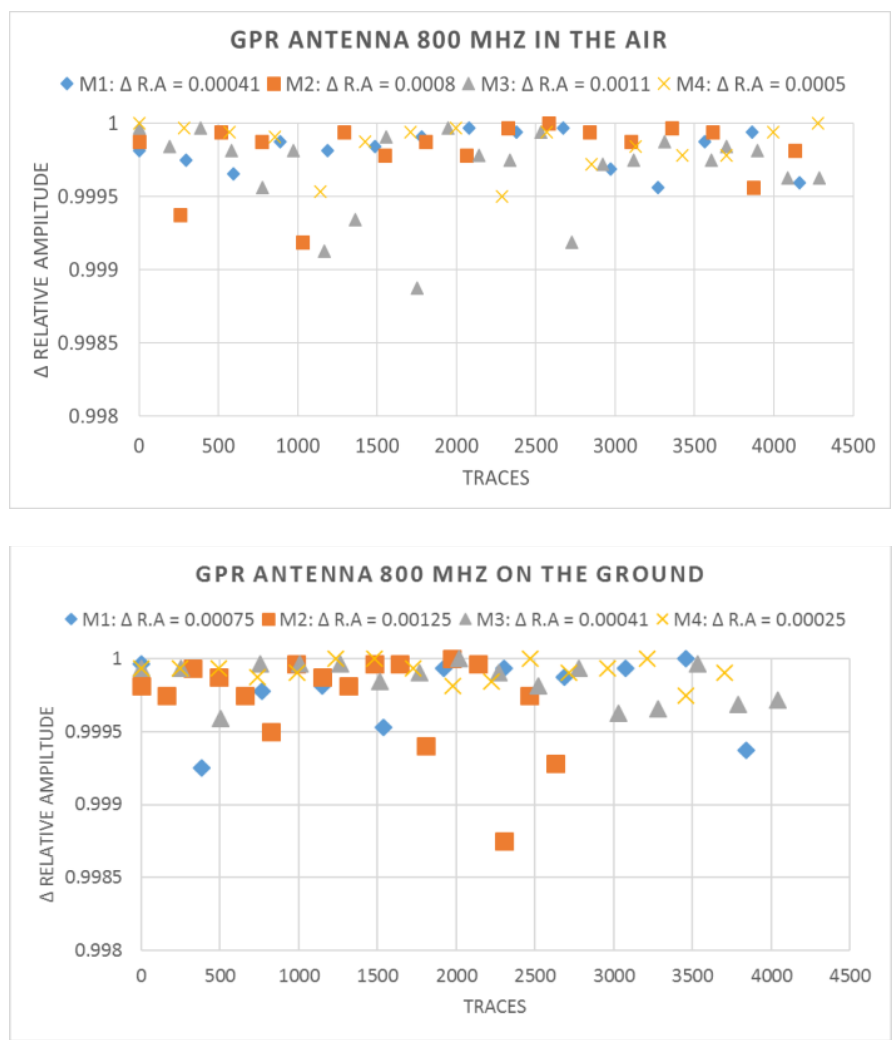

Fig. 6. Direct wave relative amplitude for the $800 \mathrm{MHz}$ centre frequency antenna
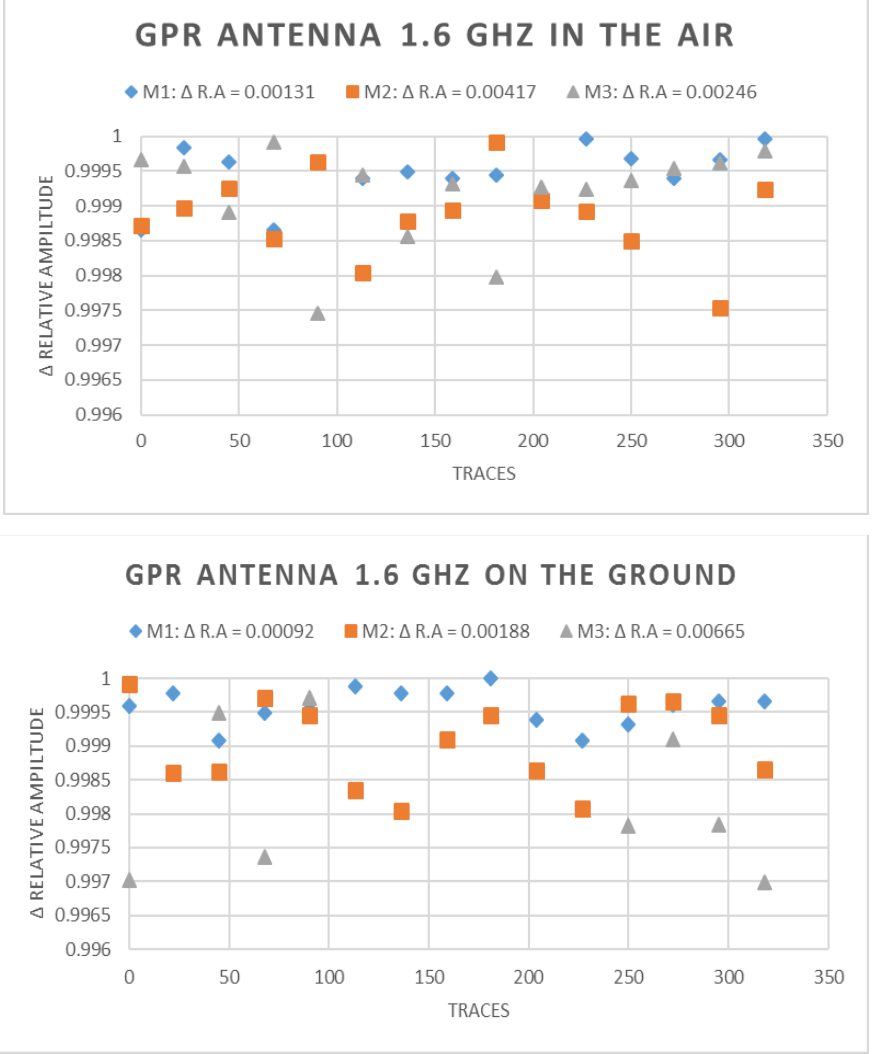

Fig. 7. Direct wave relative amplitude for the $1600 \mathrm{MHz}$ centre frequency antenna. 
TABLE 1. STABILITY AND CHANGES IN AMPLITUDE OF THE VARIOUSE SHIELDED ANTENNAS.

\begin{tabular}{|c|c|c|c|}
\hline \multirow{3}{*}{$\begin{array}{c}\text { GPR } \\
\text { Antenna }\end{array}$} & \multirow{3}{*}{$\begin{array}{c}\text { GPR } \\
\text { Measurements }\end{array}$} & $1^{\text {st }}$ Case & $2^{\text {nd }}$ Case \\
\hline & & AIR & GROUND \\
\hline & & $\Delta \mathrm{A}$ & $\Delta \mathrm{A}$ \\
\hline \multirow{4}{*}{$\sum_{\substack{\infty \\
ٍ}}^{N}$} & M1 & 0.00019 & 0.00006 \\
\hline & M2 & 0.00013 & 0.00016 \\
\hline & M3 & 0.00019 & 0.00009 \\
\hline & Average & 0.00017 & 0.00010 \\
\hline \multirow{5}{*}{$\begin{array}{l}\underset{\infty}{N} \\
\underset{\infty}{\infty}\end{array}$} & M1 & 0.00041 & 0.00075 \\
\hline & M2 & 0.00081 & 0.00125 \\
\hline & M3 & 0.00109 & 0.00041 \\
\hline & M4 & 0.00050 & 0.00025 \\
\hline & Average & 0.00070 & 0.00066 \\
\hline \multirow{4}{*}{ 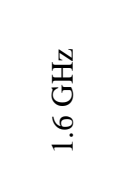 } & M1 & 0.00131 & 0.00092 \\
\hline & M2 & 0.00417 & 0.00188 \\
\hline & M3 & 0.00246 & 0.00665 \\
\hline & Average & 0.00265 & 0.00315 \\
\hline
\end{tabular}

\section{B. Time Zero}

A-scans obtained in the test exhibit the direct and the reflected wave on the metallic surface. Knowing the distance D between the antenna surface and the metallic plate, the expected two-way travel (TWT) time for the reflected wave was calculated to be $16 \mathrm{~ns}, 8 \mathrm{~ns}$ and $4 \mathrm{~ns}$ for $500 \mathrm{MHz}, 800 \mathrm{MHz}$ and $1.6 \mathrm{GHz}$, respectively, using equation 1 ;

$$
T W T=2 D / v
$$

Being $\mathrm{v}$ the wave velocity in air $(30 \mathrm{~cm} / \mathrm{ns}$ approximately)

Figure 8 presents representative examples of the A-scans obtained for each antenna. Zero-time position was determined from the reflected wave, measuring the TWT obtained in equation (1), Table 2 exhibits the average results obtained in the test.

\section{TABLE.2 ZERO POSITION OF SHIELDED ANTENNAS}

\begin{tabular}{|c|c|c|c|c|}
\hline Antennas & $\begin{array}{c}\text { Distance } \\
(\mathbf{c m})\end{array}$ & $\begin{array}{c}\text { TwT } \\
(\mathbf{n s})\end{array}$ & $\begin{array}{c}\text { Reflection } \\
\text { Wave Time } \\
(\mathbf{n s})\end{array}$ & $\begin{array}{c}\text { Zero Position } \\
\text { Time } \\
(\mathbf{n s})\end{array}$ \\
\hline $500 \mathrm{MHz}$ & 240 & 16 & 20 & 4 \\
\hline $800 \mathrm{MHz}$ & 120 & 8 & 10 & 2 \\
\hline $1.6 \mathrm{GHz}$ & 60 & 4 & 5.5 & 1.5 \\
\hline
\end{tabular}

\section{Zero Time for $500 \mathrm{MHz}$ Antenna}

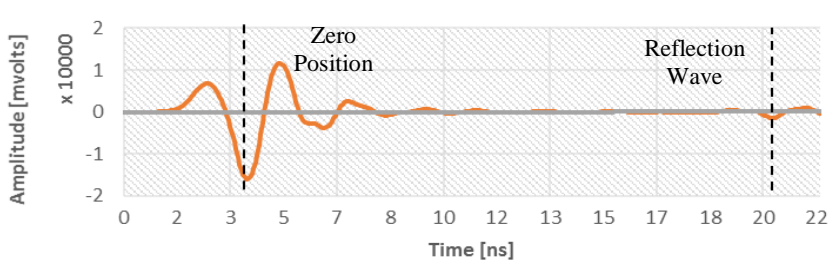

Zero Time for $800 \mathrm{MHz}$ Antenna

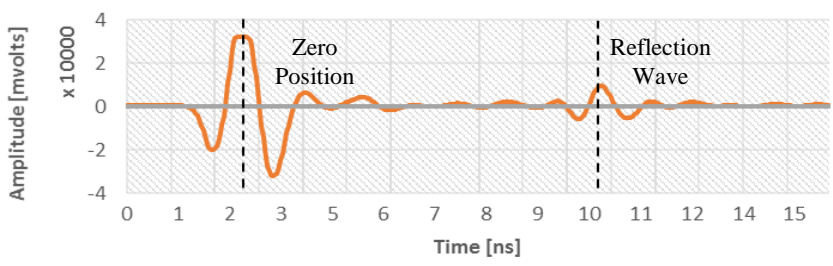

\section{Zero Time for $1.6 \mathrm{GHz}$ Antenna}

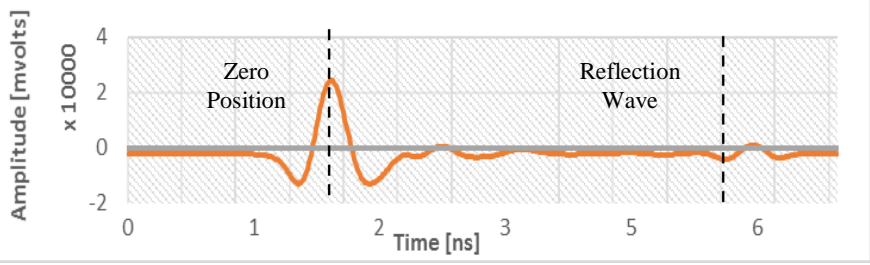

Fig. 8. Time Zero Results

\section{Stacking and Antennas Resolution}

The results from the tests to determine the effects of the stacking on the signals are shown in figures 9,10 ad 11 . Measurements were carried out with stack values of: $1,2,4,8$, $16,64,128,256$ and 512.

Results seems to indicate that the signals from $500 \mathrm{MHz}$ and $800 \mathrm{MHz}$ centre frequency antennas are quite stables. However, important changes in the signals are observed in the A-scans from the $1.6 \mathrm{GHz}$ antenna.

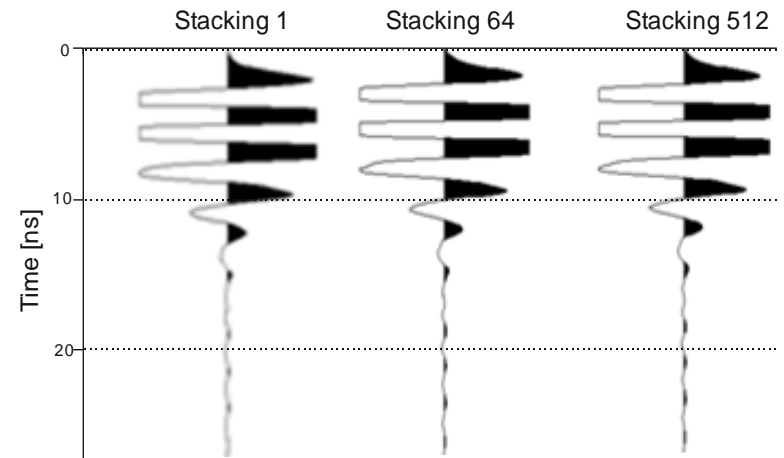

Fig. 9. Stacking values for $500 \mathrm{MHz}$ shielded antenna.

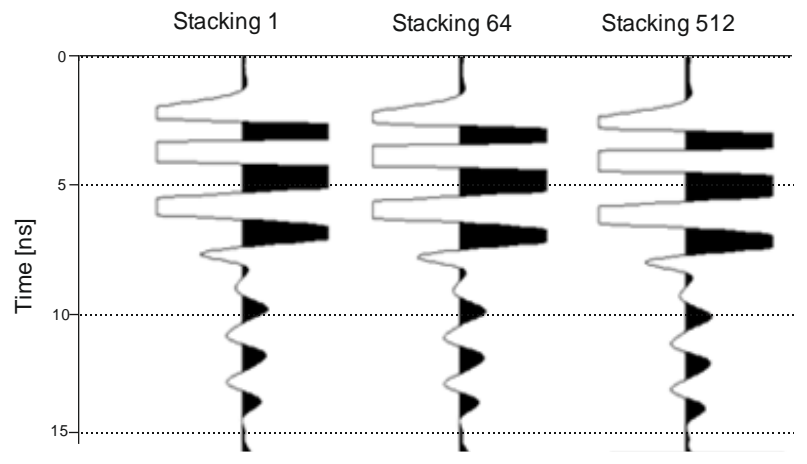

Fig. 10. Stacking values for $800 \mathrm{MHz}$ shielded antenna. 


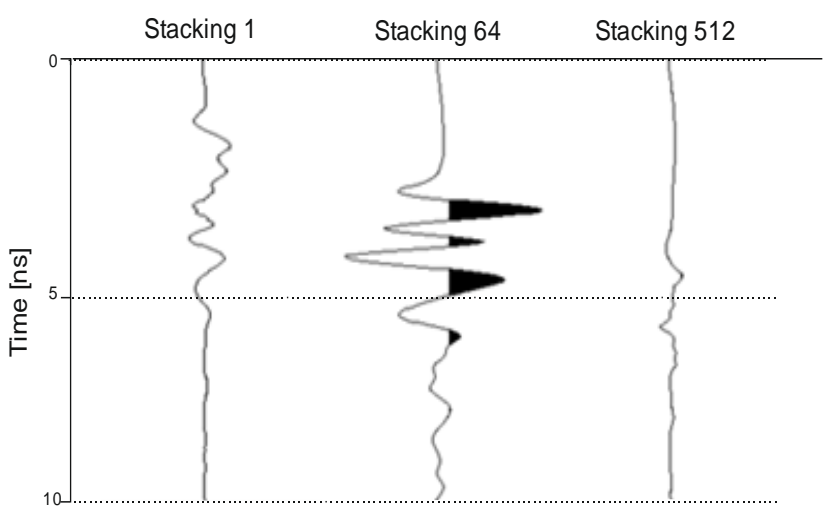

Fig. 11. Stacking values for $1.6 \mathrm{GHz}$ shielded antenna.

\section{CONCLUSIONS}

This paper presented the results obtained from different calibration tests. The objective was determining some of the characteristics of the antennas behaviour. Calibration is a crucial task previous to field data acquisition for accurate results and interpretations.

In addition, antennas calibration is recommended so often since the use and age can deteriorate them and modify their expected behaviour.

\section{A. Stability}

The stability measured with the proposed test depends on the reconstruction of the signal and on the electronics of the antenna. Results indicate that most likely changes in the amplitude of the direct wave are no higher than $1 \%$ of the maximum direct wave amplitude. This results indicates a stable emission and reception, being small the noise expected by ringing or jitter. Comparing stability of the direct wave in air and in ground, no differences can be defined, and most likely, more tests are needed in order to define a statistical results.

Stable waves also depend on the warm time. It is important to turn on the equipment and the antennas between 5 to 8 minutes before starting data acquisition. In some cases the drift time of antennas seems to be more significant than the results from other equipments and studies [9].

\section{B. Time Zero Position}

Time-zero position is not a fixed and constant point in all type of antennas. The real time-zero position of A-scans from a ground-coupled antennas depend on several factors and must be determined for each antenna individually [12]. In this case, the metal was used in order to visualize much better the reflection on the surface.

\section{Stacking}

Stacking is a procedure that could improve the radar images because it reduces noise as consequence of the instability of the GPR signal. The stack of several traces reduces the effects and the result is a more stable A-scans. This effect is clear in both shielded antennas (500 MHz and $800 \mathrm{MHz}$ ). Measurements with the $1.6 \mathrm{GHz}$ centre frequency antenna presents higher changes and instability and most likely further test are needed to determine the effect on the radar data. The suitable stacking value depends on the application and survey, and it must be selected being subjected to the shape and size of the expected targets. Time for data acquisition must be also considered in order to select the most appropriate stacking value. For example,

\section{ACKNOWLEDGMENT}

This research has been partially funded by the Ministry of Economy and Competitiveness (MINECO) of the Spanish Government and by the European Regional Development Fund (FEDER) of the European Union (UE) through projects referenced as: CGL2011-23621 and CGL2015-65913 -P (MINECO / FEDER, UE).

\section{REFERENCES}

[1] Annan, A. P. (2005). Ground-penetrating radar. In Near-surface geophysics (pp. 357-438). Society of Exploration Geophysicists.

[2] Benedetto, A., \& Pajewski, L. (Eds.). (2015). Civil engineering applications of ground penetrating radar. Springer.

[3] Daniels, D. J. (2004). Ground penetrating radar. John Wiley \& Sons, Inc.

[4] Grandjean, G., Gourry, J. C., \& Bitri, A. (2000). Evaluation of GPR techniques for civil-engineering applications: study on a test site. Journal of Applied Geophysics, 45(3), 141-156.

[5] Diamanti, N., Giannopoulos, A., \& Forde, M. C. (2008). Numerical modelling and experimental verification of GPR to investigate ring separation in brick masonry arch bridges. NDT \& E International, 41(5), 354-363.

[6] Solla, M., Riveiro, B., Lorenzo, H., \& Armesto, J. (2013). Ancient stone bridge surveying by ground-penetrating radar and numerical modeling methods. Journal of Bridge Engineering, 19(1), 110-119.

[7] Rial, F. I., Lorenzo, H., Pereira, M., \& Armesto, J. (2009). Analysis of the emitted wavelet of high-resolution bowtie GPR Antennas. Sensors, 9(6), 4230-4246

[8] Rial, F. I., Lorenzo, H., Novo, A., Pereira, M. (2011). Checking the signal stability in GPR systems and antennas. IEEE Journal of Selected Topics in Applied Earth Observations and Remote Sensing, 4(4), 785-790.

[9] Pérez-Gracia, V., González-Drigo, R., Di Capua, D., \& Pujades, L. G. (2007, October). Characteristics of the GPR field pattern antennas. In Remote Sensing for Environmental Monitoring, GIS Applications, and Geology VII (Vol. 6749, p. 67492L). International Society for Optics and Photonics.

[10] Pérez-Gracia, V., González-Drigo, R., \& Di Capua, D. (2008). Horizontal resolution in a non-destructive shallow GPR survey: An experimental evaluation. NDT \& E International, 41(8), 611-620.

[11] Pérez-Gracia, V., Di Capua, D., González-Drigo, R., \& Pujades, L. (2009). Laboratory characterization of a GPR antenna for high-resolution testing: Radiation pattern and vertical resolution. NDT \& E International, 42(4), 336-344.

[12] Yelf, R. J. (2004) 'Where is true time zero?', Proceedings of the Tenth International Conference on Grounds Penetrating Radar, 2004. GPR 2004., 1, pp. 279-282. doi: 10.1109/ICGPR.2004.179979. 